\title{
Neumonías en el inmunocomprometido: perspectiva desde el diagnóstico por imágenes, e inferencia Bayesiana
}

\author{
Mauricio Canals, Eduardo Sabbagh y Sara Chernilo
}

\section{Pneumonia in the inmunocompromised host: perspective through images diagnosis and a Bayesian inference}

Introduction: The population of immunocompromised patients has increased in recent decades . Many of these patients eventually present infectious complications including pneumonia, which is a diagnostic that must to be prompt and accurate. Objective: To review the basis of the diagnosis of pneumonia in the immunocompromised patient. Sorted by the methodology of Bayesian inference, very relevant in the diagnostic attribution, we review the main basis of the diagnosis of pneumonia of immunocompromised patients: the epidemiology, the clinical history including the type of immunosuppression that weigh the likelihood of attribution a priori of an etiologic agent, and finally, the findings in the image (or likelihood function). Conclusion: Although in general the findings are not pathognomonic and there is much overlap in the images, there are several features that orient in one direction or another. Proper assessment of the prior probability and the likelihood function is allowing ultimately a good diagnostic proposition.

Key words: Immunocompromised, pneumonia, etiology, diagnosis, images.

Palabras clave: Inmunocomprometidos, neumonía, etiología, diagnóstico, imágenes.

\section{Introducción}

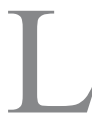

a población de pacientes inmunocomprometidos se ha incrementado en las últimas décadas ${ }^{1,2}$, lo que se encuentra asociado al envejecimiento poblacional, al aumento en la incidencia de las enfermedades neoplásicas, al tratamiento farmacológico empleado en patologías del colágeno y en trasplantes y a la pandemia de infección por $\mathrm{VIH} / \mathrm{SIDA}^{3}$. Gran parte de estos pacientes presenta en algún momento complicaciones infecciosas. Por ejemplo pacientes con cáncer recibiendo quimioterapia desarrollan a menudo neutropenia y fiebre, en conjunto con altos niveles de co-morbilidad y complicaciones infecciosas como sepsis, aspergilosis angio-invasora o neumonía por Candida spp. ${ }^{2}$, lo que se asocia a mortalidades de 5 a $20 \%{ }^{3}$.

El pulmón es uno de los órganos más frecuentemente comprometidos por infecciones en el paciente inmunocomprometido $^{4}$, dando cuenta la neumonía de alrededor de $75 \%$ de estas infecciones, con una alta morbilidad y mortalidad $^{2}$.

El diagnóstico rápido y acertado en las neumonías es muy importante y en eso juega un rol fundamental el diagnóstico por imágenes. Éste, sin embargo, se fundamenta en un adecuado conocimiento de la realidad local y de los antecedentes clínicos del paciente además de las características de la imagen. En este trabajo revisamos las bases del diagnóstico de las neumonías del inmunocomprometido poniéndolo en el contexto de los datos epidemiológicos disponibles en Chile y del tipo de inmunodepresión.

\section{Pilares diagnósticos}

En 1763 Thomas Bayes enunció su famoso teorema: "Dada una partición del espacio muestral $\mathrm{A}_{\mathrm{i}}$ (ie: conjunto de posibles diagnósticos) y un evento $\mathrm{B}$ (ie: una imagen médica), entonces la probabilidad condicional (o a posteriori) de $\mathrm{A}_{\mathrm{i}}$, dado el evento $\mathrm{B}$ (ie: la probabilidad de un determinado diagnóstico dado la imagen) es:

$$
P\left(A_{i} / B\right)=\frac{P\left(B / A_{i}\right) \cdot P\left(A_{i}\right)}{\sum_{j} P\left(B / A_{j}\right) \cdot P\left(B_{j}\right)}[1] \text {. }
$$

Este antiguo teorema nos indica que para estimar (o actualizar) la probabilidad de un determinado diagnóstico es necesario estimar la probabilidad a priori de dichos diagnósticos $\left(P\left(A_{j}\right)\right)$ y la probabilidad de tener esta imagen dado cada uno de los posibles diagnósticos (función de verosimilitud: $\left.P\left(B / A_{j}\right)\right)^{5,6}$. En términos simples, es necesario primero conocer la epidemiología que representa la realidad local en términos de frecuencias de presentación de los posibles diagnósticos y los antecedentes clínicos del paciente. Ambos en conjunto permiten establecer la probabilidad de atribución a priori, antes de ver la
Universidad de Chile, Santiago.

Facultad de Medicina

Departamento de Medicina

(Oriente) (MC).

Instituto Nacional del Tórax,

Santiago, Chile.

Servicio de Neumología (SC) Servicio de Radiología (ES).

Los autores han declarado que no existen conflictos de intereses.

No existen fuentes de financiamiento.

Recibido: 18 de abril de 2013 Aceptado: 25 de noviembre de 2013

Correspondencia a:

Mauricio Canals Lambarri mcanals@uchile.cl 
imagen, de los posibles diagnósticos. En segundo lugar es necesario tener un conocimiento acabado de las imágenes esperadas en cada diagnóstico, estableciendo la función de verosimilitud, lo que permite actualizar la distribución de probabilidades de los posibles diagnósticos. Aunque este proceso es mental y no pasa ni termina en grandes cálculos para proponer un diagnóstico, el teorema de Bayes permite identificar los pilares diagnósticos relevantes en las neumonías del paciente inmunocomprometido: Probabilidad a priori basada en la epidemiología y antecedentes clínicos, y Función de verosimilitud, basada en las imágenes.

\section{Probabilidad a priori}

\section{Epidemiología}

Las enfermedades respiratorias son una causa de morbilidad y mortalidad frecuente en la población chilena, con una tasa de 106 casos/100.000 habitantes año. Entre éstas, la neumonía constituye la tercera causa de mortalidad $(7,4 \%)$, con una tasa de mortalidad estimada de 60 casos/100.000 habitantes año en $1998^{7}$. Posteriormente, ha existido un decrecimiento de esta tasa desde 45 en 1999 a 20 casos/100.000 habitantes año en 2005, aunque en adultos mayores la tasa aún es alta cayendo desde 571 a 231 casos/100.000 habitantes año desde 1999 a 2003. La letalidad estimada en Chile por la Sociedad Chilena de Enfermedades Respiratorias es de $13 \%{ }^{8}$.

El agente etiológico de la neumonía es diferente según el origen del contagio y el estado inmunitario del paciente. Así, hoy la neumonía se clasifica en: neumonía adquirida en la comunidad (NAC), neumonía intrahospitalaria o nosocomial (NN) y neumonía del inmunocomprometido (NIC).

La etiología de las NAC en Chile es variable, pero hay una coincidencia general en los agentes involucrados. Por ejemplo, en pacientes que se hospitalizan, Fernández y cols. (2003), comunicaron como causas más frecuentes en diagnósticos definitivos: Mycoplasma pneumoniae (25\%), Chlamydophila pneumoniae (19\%) y Streptococcus pneumoniae $(13 \%)^{9}$. En cambio en 2005 , Díaz y cols., comunicaron como principales agentes: S. pneumoniae (34\%), virus parainfluenza 1 a $3(22 \%)$ y virus influenza A o B $(14 \%)^{10}$. Estos mismos autores en el años 2007 comunicaron en 98 pacientes que se hospitalizaron 53\% de bacterias "típicas", 23\% de etiología viral, 10\% de bacterias "atípicas" y $13 \%$ de infecciones mixtas. Los agentes más frecuentes fueron: $S$. pneumoniae (44\%), virus parainfluenza 1-3 (13\%) y etiología mixta (13\%) (Tabla $1)^{11,12}$. Otros microorganismos con escasa participación mencionados en este estudio, pero también mencionados en literatura médica extranjera, son: Staphylococcus aureus, Klebsiella pneumoniae, Moraxella catarrhalis y Enterococcus faecalis ${ }^{12}$.
La NN, considerada como aquella que se desarrolla en un paciente después de $72 \mathrm{~h}$ de ser internado, es la principal causa de muerte entre las infecciones adquiridas en el hospital, con una mortalidad estimada entre $20 \mathrm{y}$ $50 \%{ }^{13}$. En general se asocia a la microaspiración de secreciones orofaríngeas contaminadas con microorganismos gramnegativos que han colonizado recientemente esta región anatómica a consecuencia del reemplazo de la microbiota habitual por una más resistente, hospitalaria, y a factores asociados como el uso de antimicrobianos, hipotensión arterial, hipoxemia, acidosis metabólica, y otras co-morbilidades, además de factores mecánicos como la introducción de catéteres, intubación y ventilación mecánica ${ }^{13}$. La etiología de la NN ha ido cambiando. Mientras en la década del 50 los agentes dominantes eran S. pneumoniae, Streptococcus pyogenes y Haemophilus influenzae, en los 60 destaca $S$. aureus y a partir de los 70 cobra importancia Pseudomonas aeruginosa. Actualmente hemos de recordar que aproximadamente $30 \%$ de las $\mathrm{NN}$ son de etiología polimicrobiana. Incluso en pacientes con ventilación mecánica se ha reportado que entre 40 y $60 \%$ son polimicrobianas. En estos últimos pacientes se reporta que 55 a $85 \%$ de los casos serian causadas por $P$. aeruginosa, Acinetobacter spp. y enterobacterias, y entre 20 y $30 \%$ por $S$. aureus $^{14}$. Ramirez $(2010)^{13}$, considerando los factores: tiempo de aparición de la NN, gravedad de la misma, uso previo de antimicrobianos y riesgo de microorganismos resistentes procedentes de la comunidad, clasifica los pacientes con NN en un grupo de bajo riesgo, afectados por patógenos básicos como $S$. pneumoniae, $S$. aureus sensible a meticilina, $H$. influenzae, $M$. catarrhalis, Escherichia coli, K. pneumoniae y Proteus sp. y un grupo de alto riesgo afectado por Serratia marcescens, $P$. aeruginosa, Acinetobacter sp., Citrobacter freundii, Enterobacter cloacae, $S$. aureus resistente a meticilina y Morganella morganii.

Los pacientes inmunocomprometidos padecen neumonías por los agentes habituales en NAC y NN, pero además aparecen neumonías por microorganismos inhabituales, dependiendo del tipo de inmunocompromiso. Con fines prácticos, en este artículo clasificamos a los hospederos inmunocomprometidos en: Grupo 1: pacientes con immunocompromiso leve como pacientes ancianos, grandes fumadores, alcohólicos y pacientes con bronquiectasias, enfermedad obstructiva crónica o enfermedades pulmonares previas que aumenten la probabilidad de nuevas infecciones pulmonares como la TBC; Grupo 2: pacientes oncológicos; Grupo 3: pacientes que han sido sometidos a trasplantes y Grupo 4: pacientes con infección por VIH/SIDA ${ }^{15}$.

Grupo 1. En otros lugares se ha comunicado como agentes prevalentes de NAC en pacientes ancianos a $S$. pneumoniae, $H$. influenzae, virus influenza B; C. pneumo- 
niae, Coxiella burnetii; E. coli. Legionella pneumophila, $\mathrm{y}$ otros bacilos gramnegativos ${ }^{16,17}$. También en este grupo se ha comunicado mayor incidencia de micobacterias no-tuberculosas y de aspergilosis ${ }^{15}$. En Chile Riquelme y cols. $(2008)^{18}$, comunicaron en pacientes ancianos hospitalizados por NAC los microorganismos más fre- cuentes: H. influenzae (31,4\%), S. pneumoniae (22,8\%), bacilos gramnegativos (14,3\%), C. pneumoniae $(11,4 \%)$, $S$. aureus $(8,6 \%)$ y una etiología mixta en $25 \%$. En este mismo estudio comunican que la desnutrición aumenta la participación de $S$. pneumoniae $(40,4 \%)$ y $S$. aureus $(11,5 \%)$ (Tabla 1$)$

\begin{tabular}{|c|c|c|c|c|c|}
\hline \multirow{2}{*}{$\begin{array}{l}\text { Neumonía adquirida en la } \\
\text { comunidad }\end{array}$} & \multirow[t]{2}{*}{ Neumonía nosocomial } & \multicolumn{4}{|c|}{ Neumonía en pacientes inmunocomprometidos } \\
\hline & & IC leve & Oncológicos & Sometidos a trasplantes & Con infección por VIH \\
\hline $\begin{array}{l}\text { M. pneumoniae }(25 \%), \\
\text { C. pneumoniae }(19 \%) \\
\text { S. pneumoniae }(13 \%) \\
\text { Fernández y cols. }(2003)\end{array}$ & $\begin{array}{l}\text { Bacilos Gram(-)s, } \\
\text { P. aeruginosa, } \\
\text { Acinetobacter spp., } \\
\text { Enterobacter spp (55-85\%) } \\
\text { S. aureus (20-30\%) } \\
\text { Alvarez y cols. (2001) }\end{array}$ & $\begin{array}{l}\text { Ancianos } \\
\text { H. influenzae }(31,4 \%) \\
\text { S. pneumoniae }(22,8 \%) \\
\text { Bacilos G (-) }(14,3 \%) \\
\text { C. pneumoniae }(11,4 \%) \\
\text { S. aureus }(8,6 \%) \\
\text { L. pneumophila }(5,7 \%) \\
\text { M. pneumoniae }(2,9 \%) \\
\text { S. milleri }(2,9 \%) \\
\text { Mixta }(25 \%) \\
\text { Riquelme y cols ( } 2008)\end{array}$ & $\begin{array}{l}\text { Aumento en } \\
\text { prevalencia de: } \\
\text { Mycobacterium sp. } \\
\text { Nocardia sp. } \\
\text { Legionella sp. } \\
\text { Mycoplasma sp. } \\
\text { Chlamydophila sp. } \\
\text { P. jiroveci } \\
\text { Candida sp. } \\
\text { Aspergillus sp } \\
\text { Zygomicetes, } \\
\text { Histoplasma sp } \\
\text { Cryptococcus sp } \\
\text { VSR adenovirus, herpes } \\
\text { simplex varicela-zoster, } \\
\text { CMV, influenza } \\
\text { Toxoplasma gondii } \\
\text { Rubio y cols. (2004) }\end{array}$ & $\begin{array}{l}\text { Trasplantes de células } \\
\text { madre } \\
\text { Antes del injerto: } \\
\text { bacterias y hongos } \\
\text { oportunistas como } \\
\text { Aspergillus sp. y } \\
\text { Candida sp. } \\
\text { Después del injerto: } \\
\text { Virus como CMV } \\
\text { Muller y cols., (2007) }\end{array}$ & $\begin{array}{l}\text { P. jiroveci }(37,71 \%) \\
\text { bacterias habituales en } \\
\text { NAC }(23,3 \%) \\
\text { M. tuberculosis }(12,2 \%) \\
\text { Mixta }(8,1 \%) \\
\text { Mycobacterium } \\
\text { no-tuberculosos }(2,1 \%) \\
\text { Bacterias no habituales } \\
(1,7 \%) \\
\text { Virus }(1,3 \%) \\
\text { Aspergillus sp. }(0,42 \%) \\
\text { CMV }(0,4 \%) \\
\text { Chernilo y cols. }(2005)\end{array}$ \\
\hline $\begin{array}{l}\text { S. pneumoniae (34\%) } \\
\text { Parainfluenza } 1-3 \text { (22\%). } \\
\text { Influenza A o B (14\%) } \\
\text { C. pneumoniae (6\%) } \\
\text { M. pneumoniae (6\%), } \\
\text { H. influenzae (5\%) } \\
\text { S. marcescens (5\%). } \\
\text { Díaz y cols. (2005) }\end{array}$ & $\begin{array}{l}\text { Bajo riesgo } \\
\text { S. pneumoniae, } \\
\text { S. aureus MS } \\
\text { H. influenzae } \\
\text { M. catarrhalis } \\
\text { E. coli, } \\
\text { K. pneumoniae } \\
\text { Proteus sp. }\end{array}$ & $\begin{array}{l}\text { Desnutridos } \\
\text { S. pneumoniae }(40,4 \%) \\
\text { S. aureus }(11,5 \%) \text {. } \\
\text { Riquelme y cols. (2008) }\end{array}$ & & $\begin{array}{l}\text { Trasplantes de órganos } \\
\text { sólidos } \\
\text { Antes de } 1 \text { mes: } \\
\text { lgual que inmunocompe- } \\
\text { tentes } \\
\text { Del } 1 \text { al } 6 \text { to mes: } \\
\text { CMV, VEB, herpes simplex } \\
\text { pueden predisponer a: } \\
\text { P. jiroveci } \\
\text { A. fumigatus }\end{array}$ & $\begin{array}{l}\text { P. jiroveci }(52,6 \%) \\
\text { S. pneumoniae }(12,3 \%) \\
\text { M. avium-c }(12,3 \%) \\
\text { S. aureus }(7 \%) \\
\text { M. tuberculosis }(5,3 \%) \\
\text { Influenza A }(3,6 \%) \\
\text { C. neoformans, } \\
\text { A. baumannii, } \\
\text { S. agalactiae } \\
\text { H. influenzae } \\
\text { M. pneumoniae } \\
\text { C. pneumoniae. } \\
\text { Perez y cols. (2011) }\end{array}$ \\
\hline $\begin{array}{l}\text { S. pneumoniae (44\%) } \\
\text { Parainfluenza 1-3 (13\%) } \\
\text { Mixta (13\%), } \\
\text { Influenza A o B ( } 8 \%) \\
\text { H. influenzae (5\%), } \\
\text { L. pneumophila (4\%) } \\
\text { M. pneumoniae (3\%) } \\
\text { C. pneumoniae (3\%). } \\
\text { Díaz y cols. (2007) }\end{array}$ & $\begin{array}{l}\text { Alto riesgo } \\
\text { S. marcescens } \\
\text { P. aeruginosa } \\
\text { Acinetobacter sp. } \\
\text { C. freundii } \\
\text { E. cloacae } \\
\text { S. aureus RM } \\
\text { M. morganii } \\
\text { Ramírez y cols. (2011) }\end{array}$ & & & $\begin{array}{l}\text { Después del 6to mes: } \\
\text { Depende del estado in- } \\
\text { munitario } \\
\text { Los más frecuentes en } \\
\text { trasplante de precurso- } \\
\text { res hematopoyéticos: } \\
\text { Bacilos Gram(-)s } \\
\text { S. aureus } \\
\text { Herpes simplex, CMV } \\
\text { P. jiroveci } \\
\text { Candida sp. } \\
\text { Aspergillus sp. } \\
\text { Cryptococcus sp. } \\
\text { Ho y cols., (2000) }\end{array}$ & $\begin{array}{l}\text { En niños: } \\
\text { CMV } \\
\text { M. tuberculosis } \\
\text { P. jiroveci } \\
\text { Brockman y cols. (2007) }\end{array}$ \\
\hline
\end{tabular}


Grupo 2. Los pacientes oncológicos presentan un inmunocompromiso a consecuencia de varios factores: alteración de las barreras cutáneo-mucosas primaria (por erosiones o mucositis) o secundaria al tratamiento (punciones venosas etc.), alteración de la inmunidad celular a consecuencia de la propia enfermedad o del tratamiento; alteración de la inmunidad humoral (como en el mieloma múltiple); neutropenia, desnutrición; exposición hospitalaria y procedimientos quirúrgicos ${ }^{2}$. A consecuencia de esto, ocurren ciertos cambios en la microbiota causante de neumonías, especialmente en los pacientes neutropénicos, donde aumenta la participación de Mycobacterium spp., Nocardia spp., Legionella spp., Mycoplasma spp., entre las bacterias; Pneumocystis jiroveci, Candida spp., Aspergillus spp., Zygomicetes, Histoplasma spp y Criptococcus spp., entre los hongos, virus respiratorio sincicial, adenovirus, herpes simplex, varicela-zoster, citomegalovirus (CMV) e influenza entre los virus y Toxoplasma gondii entre los protozoos ${ }^{2}$.

Grupo 3. Las complicaciones infecciosas en pacientes que reciben precursores hematopoyéticos se han clasificado de acuerdo al período de presentación de la infección en temprana (pre-injerto) si ocurre antes de 100 días del trasplante y tardía (post injerto) en caso contrario. Durante la primera fase, los pacientes presentan una neutropenia muy acentuada $\left(<500\right.$ céls $\left./ \mathrm{mm}^{3}\right)$ quedando expuestos a bacterias y hongos oportunistas. En la fase post-injerto los virus son los patógenos más comunes ${ }^{15}$. En los receptores de órganos sólidos se describen tres períodos importantes $^{1,19}$ : en el primer mes los microorganismos son los mismos que afectan a pacientes sin inmunocompromiso; entre los meses 1 y 6 virus como citomegalovirus, virus de Epstein-Barr y herpes simplex son causas potenciales de infección pulmonar y pueden predisponer a neumonías oportunistas causadas por $P$. jiroveci y A. fumigatus. Después de los 6 meses del trasplante, 75 a $85 \%$ de los pacientes quedan con un buen injerto y con adecuada inmunidad similar a los no-trasplantados, 5 a $10 \%$ persisten con un injerto no óptimo y requieren altos niveles de inmunosupresión quedando expuestos a microorganismos oportunistas, y 5 a $10 \%$ de los pacientes tienen infecciones virales crónicas asociadas a falla del órgano ${ }^{19}$. La mayoría de las neumonías post-trasplante son causadas por bacilos gramnegativos o $S$. aureus entre las bacterias, herpes simplex y CMV entre los virus, $P$. jiroveci, Candida spp., Aspergillus spp. y Criptococcus spp., entre los hongos ${ }^{2}$.

Grupo 4: Una sucesión de microorganismos afectan a los pacientes con infección por VIH/SIDA dependiendo del recuento de linfocitos $\mathrm{CD}_{4}$. Sobre 200 céls $/ \mathrm{mm}^{3}$ son frecuentes $S$. pneumoniae, $H$. influenzae, $S$. aureus y M. tuberculosis; bajo 200 céls $/ \mathrm{mm}^{3}$ son frecuentes $P$. jiroveci y $M$. tuberculosis y cuando el recuento cae bajo
100 céls $/ \mathrm{mm}^{3}$ hacen su aparición las micobacterias no tuberculosas, Aspergillus spp. y citomegalovirus ${ }^{15,20}$. En Chile, en pacientes con SIDA y neumonía, Chernilo y cols. $(2005)^{21}$, comunicaron $38,1 \%$ de causas micóticas, $25,0 \%$ bacterianas no micobacterias, $14,4 \%$ micobacterias, $1,7 \%$ virales y $8,1 \%$ de etiología mixta. Pérez y cols. $(2011)^{22}$, comunicaron $8,8 \%$ de etiología mixta y $50 \%$ de positividad a citomegalovirus en lavado bronquio-alveolar. Además describieron $P$. jiroveci (52,6\%), S. pneumoniae (12,3\%), complejo M. avium (12,3\%), S. aureus $(7 \%)$ y M. tuberculosis $(5,3 \%)$ como agentes más frecuentes. Brockman y cols. $(2007)^{23}$, comunicaron en 17 pacientes pediátricos la presencia de CMV (n: 4), M. tuberculosis (n: 1) y P. jiroveci (n: 1) (Tabla 1).

\section{Antecedentes clínicos}

La exposición ambiental es un antecedente muy importante, especialmente en infecciones por hongos. El antecedente de infecciones respiratorias es también muy relevante; por ejemplo, se ha propuesto que $M$. tuberculosis, $P$. jiroveci, $T$. gondii o virus varicela zoster son más frecuentes como reactivación que como infección nueva ${ }^{2}$. Por otra parte, se ha descrito que la infección por un microorganismo oportunista favorece la infección por otro nuevo ${ }^{24}$. Así por ejemplo, en pacientes con SIDA la infección por $P$. jiroveci aumenta la probabilidad de una infección por $M$. avium- $c^{2}$. El uso de fármacos por neoplasias y enfermedades crónicas auto-inmunes se asocia a neutropenia y monocitopenia y mucositis intestinal las que favorecen la infección por bacilos gramnegativos. Los corticosteroides disminuyen la población de linfocitos y monocitos, deprimen la fagocitosis y la actividad de los linfocitos $\mathrm{T}$ aumentando la probabilidad de infecciones respiratorias mediadas por la inmunidad celular y la fagocitosis. El antecedente de exposición hospitalaria asociada a procedimientos como intubación, antimicrobianos e inhibidores de la acidez gástrica aumentarán la probabilidad de infecciones por bacterias gramnegativas como P. aeruginosa, Enterobacter sp., Klebsiella sp., E. coli, Acinetobacter sp. ${ }^{13}$.

En el paciente inmunocomprometido, las causas subyacentes a la depresión inmune son relevantes. Puede haber: defecto en la fagocitosis, déficit de inmunidad humoral, déficit de inmunidad celular, defecto en el sistema del complemento o hiposplenia/asplenia. Cuando hay defectos en la fagocitosis (i. e. neutropenia) se ven favorecidas las infecciones por bacilos gramnegativos aerobias como $P$. aeruginosa, $K$. pneumoniae y E.coli, por $S$. aureus y hongos como Candida spp. y Aspergillus spp., mientras en el déficit de inmunidad humoral y alteración de la opsonización se verán favorecidas las bacterias encapsuladas como S. pneumoniae; $H$. influenzae y $S$. aureus. En cambio los déficit en la cadena del complemento C5 a C9 se encuentran asociados a infecciones por Neisseria sp. y 


\begin{tabular}{|c|c|c|c|}
\hline Tipo de depresión inmune & Mecanismo afectado & Organismos favorecidos & Causas habituales \\
\hline Fagocitosis & $\begin{array}{l}\text { Mononucleares (monocitos y macrófagos) } \\
\text { y neutrófilos (PMN) fagocitan bacterias y } \\
\text { hongos } \\
\text { Presentación de } \mathrm{Ag}\end{array}$ & $\begin{array}{l}\text { S. aureus, Bacilos, G(-)s aerobios (P. aerugi- } \\
\text { nosa, K pneumoniae, E.coli) } \\
\text { Candida spp, Aspergillus spp }\end{array}$ & $\begin{array}{l}\text { Neutropenia (leucemia, depresión medular } \\
\text { por quimioterapia) } \\
\text { Enfermedades granulomatosas crónicas } \\
\text { Corticoterapia } \\
\text { Hiper IgE (síndrome de Job) }\end{array}$ \\
\hline Inmunidad humoral & $\begin{array}{l}\text { Linfocitos B } \\
\text { Neutralización } \\
\text { Opsonización } \\
\text { Activación del complemento }\end{array}$ & $\begin{array}{l}\text { Bacterias extracelulares encapsuladas: } \\
\text { S. pneumoniae } \\
\text { H. influenzae } \\
\text { S. aureus }\end{array}$ & $\begin{array}{l}\text { Primaria: agamaglobulinemia, déficit de IgA, } \\
\text { déficit de IgM } \\
\text { Secundaria: mieloma, Waldestroem, leuce- } \\
\text { mia linfocítica }\end{array}$ \\
\hline Complemento & $\begin{array}{l}\text { Ayuda a la opsonización } \\
\text { Atrae células inflamatorias } \\
\text { Elimina microorganismos afectando su } \\
\text { membrana }\end{array}$ & $\begin{array}{l}\text { C3-C5: Bacterias capsuladas } \\
\text { C5-C9: Neisseria gonorrhoeae, Neisseria } \\
\text { meningitidis }\end{array}$ & Mixta \\
\hline Inmunidad celular & $\begin{array}{l}\text { Linfocitos T } \\
\text { Tc(CD8) Matan células infectadas con pató- } \\
\text { genos } \\
\text { TH1(CD4) activan macrófagos } \\
\text { TH2(CD4) activan L B para producir acpos. }\end{array}$ & $\begin{array}{l}\text { M. tuberculosus, M avium-c, N. asteroides, } \\
\text { Legionella sp., C. neoformans, } \\
\text { H. capsulatum, C. immitis, varicela zoster, } \\
\text { herpes simplex, CMV, VEB, P. jiroveci, } \\
\text { T. gondii }\end{array}$ & $\begin{array}{l}\text { Primarias } \\
\text { Secundarias: malnutrición, linfoma, } \\
\text { leucemia, edad avanzada, fármacos, SIDA } \\
\text { corticosteroides }\end{array}$ \\
\hline Hiposplenia/asplenia & $\begin{array}{l}\text { Filtra sangre } \\
\text { Produce acpos. bacteria-específicos } \\
\text { Remueve bacterias recubiertas de acpos. }\end{array}$ & Bacterias capsuladas & $\begin{array}{l}\text { Púrpura trombocitopénico trombótico, } \\
\text { Hodgkin }\end{array}$ \\
\hline
\end{tabular}

el déficit de la inmunidad celular favorecerá la infección por parásitos intracelulares como micobacterias, Nocardia sp., etc ${ }^{2}$ (Tabla 2).

\section{Imágenes (Función de verosimilitud)}

Las imágenes deben ser de la mejor calidad posible. En radiología simple son técnicas de alto voltaje $(120 \mathrm{kV})$ para obtener gran cantidad de tonos de gris (adecuada latitud) y tiempos de exposición cortos. La radiología digital permite el manejo de la curva de Hurter-Driffield ajustando la latitud y manejando el contraste, aunque requiere un muy buen ajuste de la curva para obtener una buena imagen. Para el análisis del parénquima pulmonar en tomografía axial computada (TAC) se requiere una técnica de alta resolución, con la colimación más pequeña posible $(<1,5 \mathrm{~mm})$, con algoritmos de reconstrucción de alta frecuencia espacial, cortos tiempos de exposición y 120 a 140 kV. Para el análisis es también es necesario un buen manejo de las ventanas pulmonar y mediastínica.

La neumonía, tanto en radiología simple como en TAC, se expresa radiológicamente mediante tres patrones generales: neumonía lobar, bronconeumonía y neumonía intersticio-alveolar ${ }^{15}$. Además hay un conjunto de signos radiológicos asociados como efusión pleural, nódulos, broncograma aéreo y cavitación, evidentes en radiología simple y otros como opacidad en "vidrio esmerilado", "árbol en brote", "signo del halo", adenopatías, etc, evidentes en la TAC, que orientan hacia el diagnóstico etiológico ${ }^{15}$. En el paciente inmunocomprometido se ha propuesto que es más útil considerar tres patrones fundamentales: consolidación, sea esta parcheada, segmentaria o lobar, nódulos con o sin cavitación y neumonía intersticial ${ }^{2,25}$ (Figura 1). Las consolidaciones sugerirían bacterias o micobacterias, los nódulos están asociados a diseminación hematógena y a hongos y bacterias filamentosas como $N$. asteroides, y las neumonías intersticiales asociadas a virus o $P$. jiroveci.

La evolución clínica es también relevante. Así, el curso agudo indica probablemente una bacteria agresiva, mientras que el curso sub-agudo puede sugerir micobacterias $\mathrm{u}$ hongos.

A continuación revisaremos las características de imágenes de los microorganismos más frecuentes del hospedero inmunocomprometido.

\section{Bacterias}

El grupo ESKAPE. Este grupo incorpora un conjunto de bacterias aerobias y aerobias facultativas que pueden ser causa de neumonía, especialmente en pacientes oncológicos que habitualmente son neutropénicos y que por estar bajo tratamientos farmacológicos de alta agresividad y habitualmente sometidos a procedimientos, están expuestos microbiota hospitalaria y a la diseminación hematógena. ESKAPE (sensu Quilitz) es una sigla artificial nemotécnica que agrupa a Enterococcus sp., $S$. aureus, K. pneumoniae, A. baumannii, P. aeruginosa y Enterobacter sp. Además el grupo KAPE incluye a los principales bacilos gramnegativos productores de 
neumonías. Así, en 2004 sobre neumonías de pacientes inmunocompetentes e inmunocomprometidos en conjunto, tipificadas por el Programa SENTRY en Latinoamérica entre 1997 y 1999, se obtuvo una participación porcentual de: Enterococcus sp. (2\%), S. aureus (23\%), K. pneumoniae (11\%), A. baumannii (9\%), P. aeruginosa $(25 \%)$ y Enterobacter sp. $(5 \%)^{26}$.

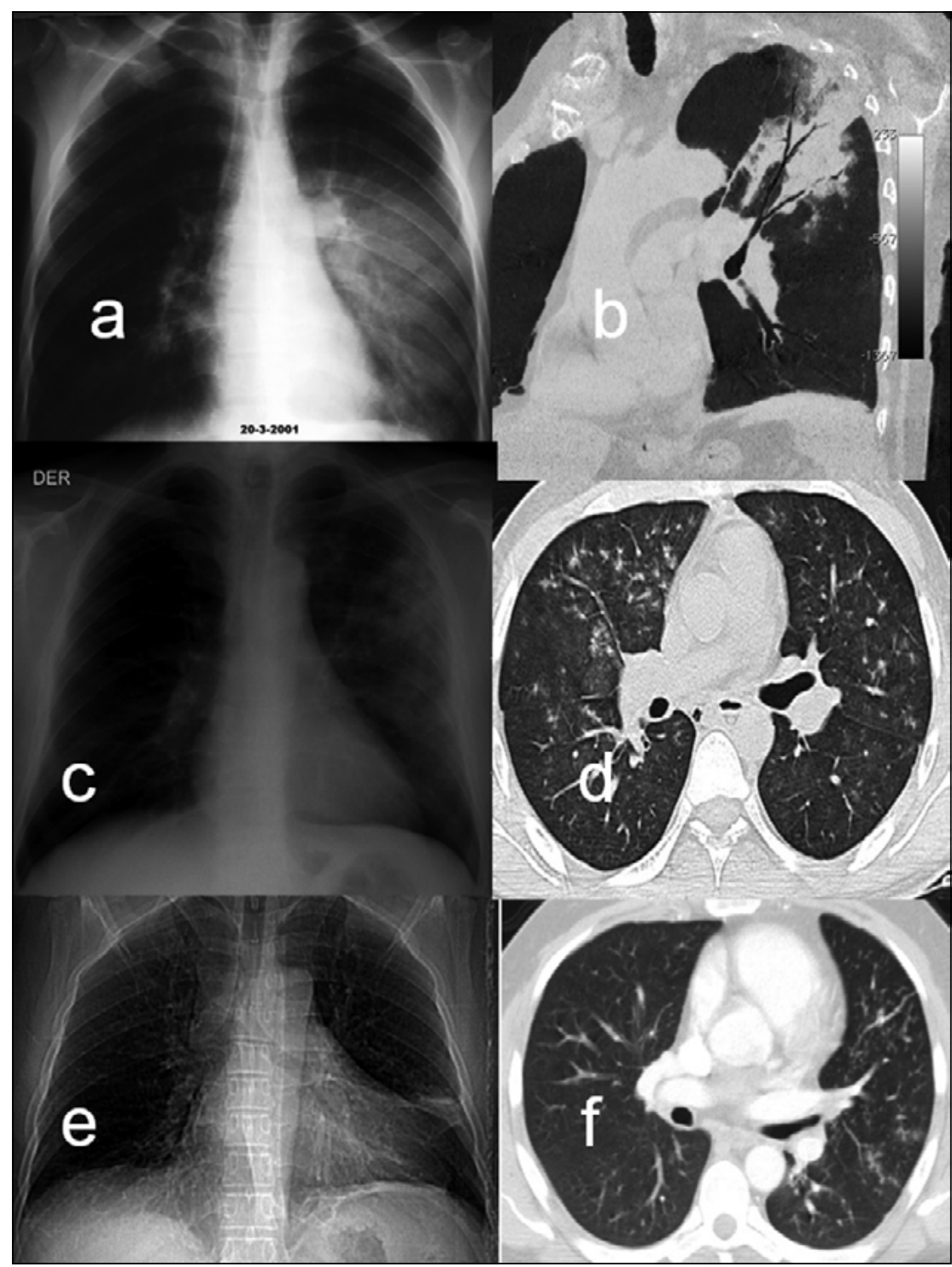

Figura 1. Patrones neumónico $(a, b)$, bronconeumónico $(c, d)$ e intersticio-alveolar $(e, f)$ en pacientes inmunocomprometidos. En a) radiografía de tórax PA: consolidación en el lóbulo inferior izquierdo que correspondió a neumonía neumocóccica en paciente con infección por $\mathrm{VIH}$; b) TAC con reconstrucción oblicua con MIP: consolidación en el lóbulo superior izquierdo que correspondió a neumonía en paciente oncológico; c) radiografía de tórax PA: opacidades parchedas siguiendo la distribución segmentaria en bronconeumonía en paciente oncológico; d) TAC multicorte ( $3 \mathrm{~mm}$ ), ventana pulmonar: opacidades y nódulos centrilobulillares en bronconeumonía en paciente oncológico; e-f) radiografía de tórax y TAC: opacidades intersticiales en las bases, tenues opacidades intersticiales e imagen de "árbol en brote" en paciente oncológico con neumonía por M. pneumoniae.
La apariencia radiológica en inmunocomprometidos, aunque es muy variable, no es esencialmente diferente de lo que se encuentra en inmunocompetentes ${ }^{2}$. Incluye los patrones de neumonía lobar en el caso de K. pneumoniae y ocasionalmente en Enterobacter sp., y patrón bronconeumónico de distribución segmentaria en los demás. Las neumonías lobares se caracterizan por consolidación, broncograma aéreo y el borramiento de estructuras vecinas ("signo de la silueta"), mientras que el patrón bronconeumónico es parcheado, de distribución segmentaria y en la TAC se manifiesta como nódulos centrilobulillares, opacidades ramificadas que recuerdan la imagen de "árbol en brote" reflejando el exudado inflamatorio endoluminal y la inflamación peribronquiolar ${ }^{27,28}$.

Klebsiella pneumoniae produce generalmente una consolidación lobar (Figura 2) con gran tendencia a producir gran cantidad de exudado inflamatorio que resulta en una expansión del lóbulo comprometido curvando las cisuras $(30 \%)$ y con frecuente cavitación y formación de abscesos y efusión pleural, en 60 a $70 \%$ de los $\operatorname{casos}^{29}$. $P$. aeruginosa se manifiesta, en general, como una bronconeumonía extensa con compromiso pan-lobular y ocasionalmente puede tener opacidades nodulares o compromiso reticular ${ }^{30}$. La cavitación ocurre en alrededor

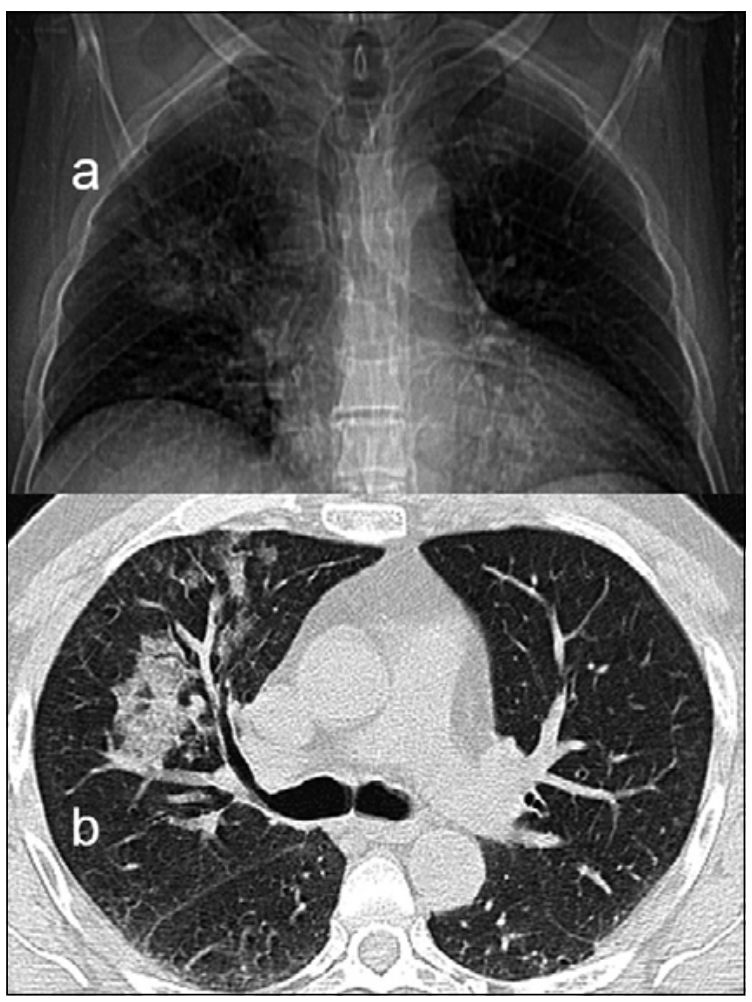

Figura 2. a y b) radiografía digital de tórax PA y corte transversal en TAC: opacidad parenquimatosa con caracteres de consolidación en el lóbulo superior derecho en neumonía por Klebsiella sp en paciente oncológico. 
de $21,4 \%$, la efusión pleural en $23,2 \%$ y pueden formarse neumatoceles en $7,1 \%$ de los casos. Además en una baja proporción pueden presentar empiema ${ }^{30}$.

Staphylococcus aureus. Cuando la neumonía por $S$. aureus se presenta en un paciente inmunocompetente se manifiesta como una bronconeumonía con distribución segmentaria que refleja la inflamación peribronquiolar. En la TAC aparecen consolidaciones, nódulos centrilobulillares y ramificaciones en "árbol en brote" en alrededor de $40 \%$ de los $\operatorname{casos}^{15,28}$. Macfarlane y Rose $(1996)^{31}$ describieron como hallazgos radiológicos en 26 pacientes con neumonía por $S$. aureus adquirida en la comunidad, consolidación homogénea (54\%), consolidaciones irregulares $(46 \%)$ y patrones mixtos en $8 \%$. Kaye y cols. $(1990)^{32}$, comunicaron consolidaciones multilobares en $60 \%$ y $39 \%$ con compromiso bilateral. Los abscesos son comunes, en 15 a $30 \%$ y el neumatocele en $50 \%$ de los niños y $15 \%$ de los adultos. La efusión pleural ocurre en 30 a $50 \%$ de los pacientes y cerca de la mitad de éstos con carácter de empiema ${ }^{31,32}$. En hospederos inmunocomprometidos, la neumonía por $S$. aureus puede seguir el patrón clásico, por ejemplo en pacientes con SIDA, receptores de trasplantes sólidos e inmunocomprometidos leves ${ }^{15}$. Sin embargo, también es muy frecuente la diseminación hematógena (émbolos sépticos) (Figura 3) que se manifiestan como imágenes nodulares de predominio sub-pleural en la radiografía y en la TAC. Muchos de ellos se cavitan y en la TAC se puede apreciar el signo del "vaso aferente", un vaso que llega al nódulo, en 40 a $70 \%$ de los casos. También es habitual observar imágenes "en cuña" subpleurales que representan infartos sépticos ${ }^{15}$.

Anaerobios estrictos. Las neumonías por anaerobios estrictos son generalmente aspirativas, lo que se expresa en una distribución dominante en los segmentos posteriores de los lóbulos superiores y los segmentos apicales de los lóbulos inferiores ${ }^{33}$. La cavitación es frecuente (20-60\%) y muchas veces se presenta como una neumonía necrosante con efusión pleural o franco empiema, en 50\% de $\operatorname{los} \operatorname{casos}^{15}$. Algunos autores proponen que ocurren más frecuentemente en pacientes hospitalizados ${ }^{15}$, En hospederos inmunocomprometidos las imágenes no son diferentes pero los cuadros clínicos son más complejos y con mayor mortalidad ${ }^{34}$.

\section{Mycobacterium spp.}

Mycobacterium tuberculosis. El mayor riesgo de desarrollar una tuberculosis (TBC) activa se encuentra en los pacientes con déficit de la inmunidad celular como ancianos, malnutridos, pacientes oncológicos, pacientes con terapia inmunosupresora, diabetes mellitus, enfermedades renales terminales y pacientes con SIDA. Así, se ha reportado en pacientes con SIDA que el riesgo de adquirir TBC es entre 20 y 100 veces superior al de los individuos normales, que la co-infección entre TBC y VIH

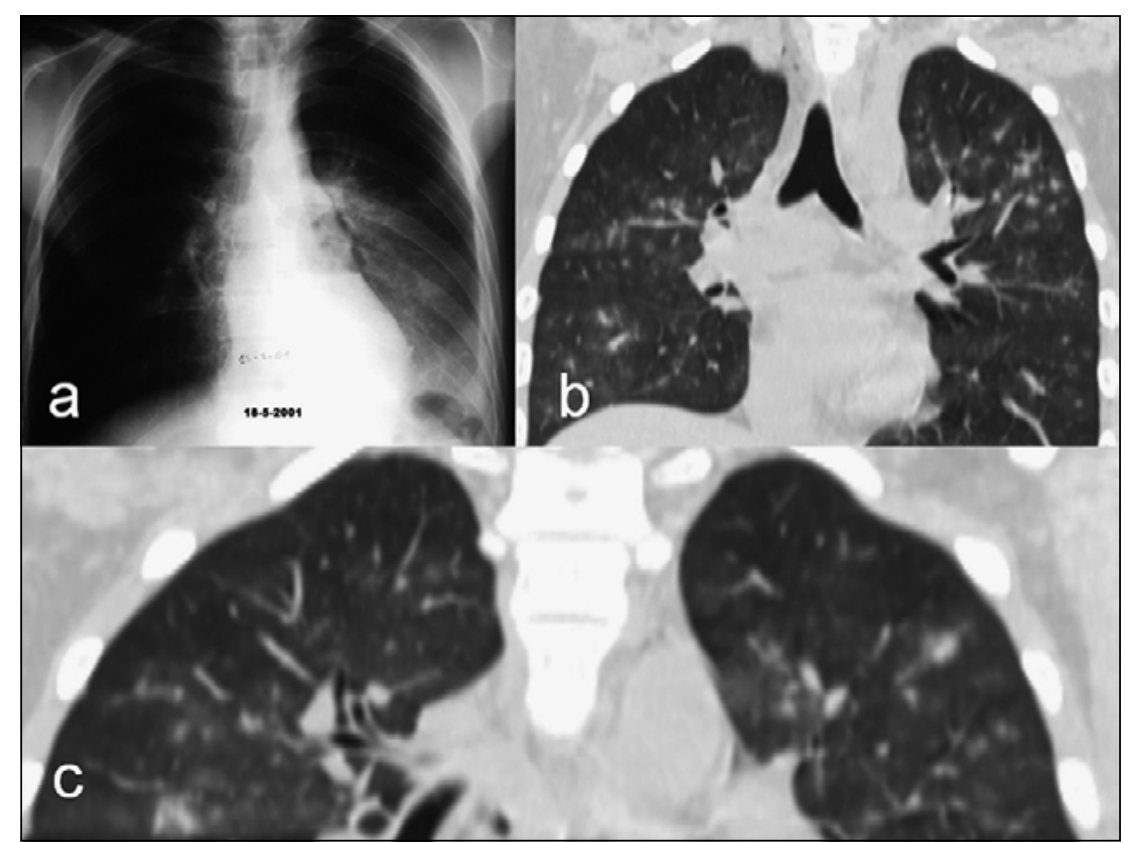

Figura 3. a) radiografía de tórax: Opacidad con caracteres de consolidación en el lóbulo inferior izquierdo, con imagen cavitaria radiolúcida con nivel hidro-aéreo retro-cardíaco en neumonía por $S$. aureus en paciente con infección por VIH; b y c) TAC de tórax, cortes transversales de 3 mm: nódulos con tenue halo periférico y uno con nivel hidro-aéreo en diseminación hematógena por $S$. aureus en una paciente inmunodeprimida portadora de un cáncer de mama.

es de $33,3 \%$ y que $8-10 \%$ de estos pacientes va a enfermar de TBC en algún momento, aunque esto disminuye a 1\% con $\mathrm{TARV}^{35}$. La TBC en el paciente inmunodeprimido adquiere formas especiales (Figura 4) ${ }^{36}$. Así Chernilo y cols. $(2005)^{21}$, describió en pacientes con SIDA una importante proporción de formas pleurales, ganglionares y miliares: pulmonar (44,8\%), miliar (10,3\%), ganglionar $(34,5 \%)$ y pleural $(10,3 \%)$. Al comparar pacientes infectados por $\mathrm{VIH}(+)$ con no infectados se han reportado en infectados por VIH: cavitaciones (19-24\%), consolidación (43\%), diseminación endobronquial (57\%), miliar (17\%), ganglionar $(70 \%)$; en pacientes no infectados por VIH: cavitaciones $(49-55 \%)$, consolidación $(69 \%)$, diseminación endobronquial $(90 \%)$, miliar $(0 \%)$ y ganglionar $(33 \%)^{37,38}$. Así, la TBC en hospederos inmunocomprometidos es similar a la TBC primaria, mientras en personas inmunocompetentes predominan la cavitación, la pérdida de volumen, la fibrosis y la calcificación ${ }^{15}$.

Micobacterias no-tuberculosas. Las micobacterias oportunistas son M. avium, M. intracellulare, M. scofulaceum, M. kansasii, M. xenopi, $M$. marinum, M. chelonae y $M$. fortuitum, y los saprofíticos como $M$. gordonae y M. terrae. Son bacterias ambientales asociadas al suelo y agua $^{15,39}$. Han aumentado su prevalencia a consecuencia de la epidemia de infección por VIH, al aumento de la expectativa de vida y a la alta prevalencia de patología 
Figura 4. a y b) radiografía de tórax PA y corte transversal de TAC: múltiples nódulos pequeños de baja densidad, de distribución aleatoria con mayor respeto en las bases en TBC miliar en paciente con infección por VIH; c) TAC cortes transversales con ventana mediastínica: múltiples adenopatías mediastínicas con centro necrótico de origen TBC en paciente con infección por VIH.

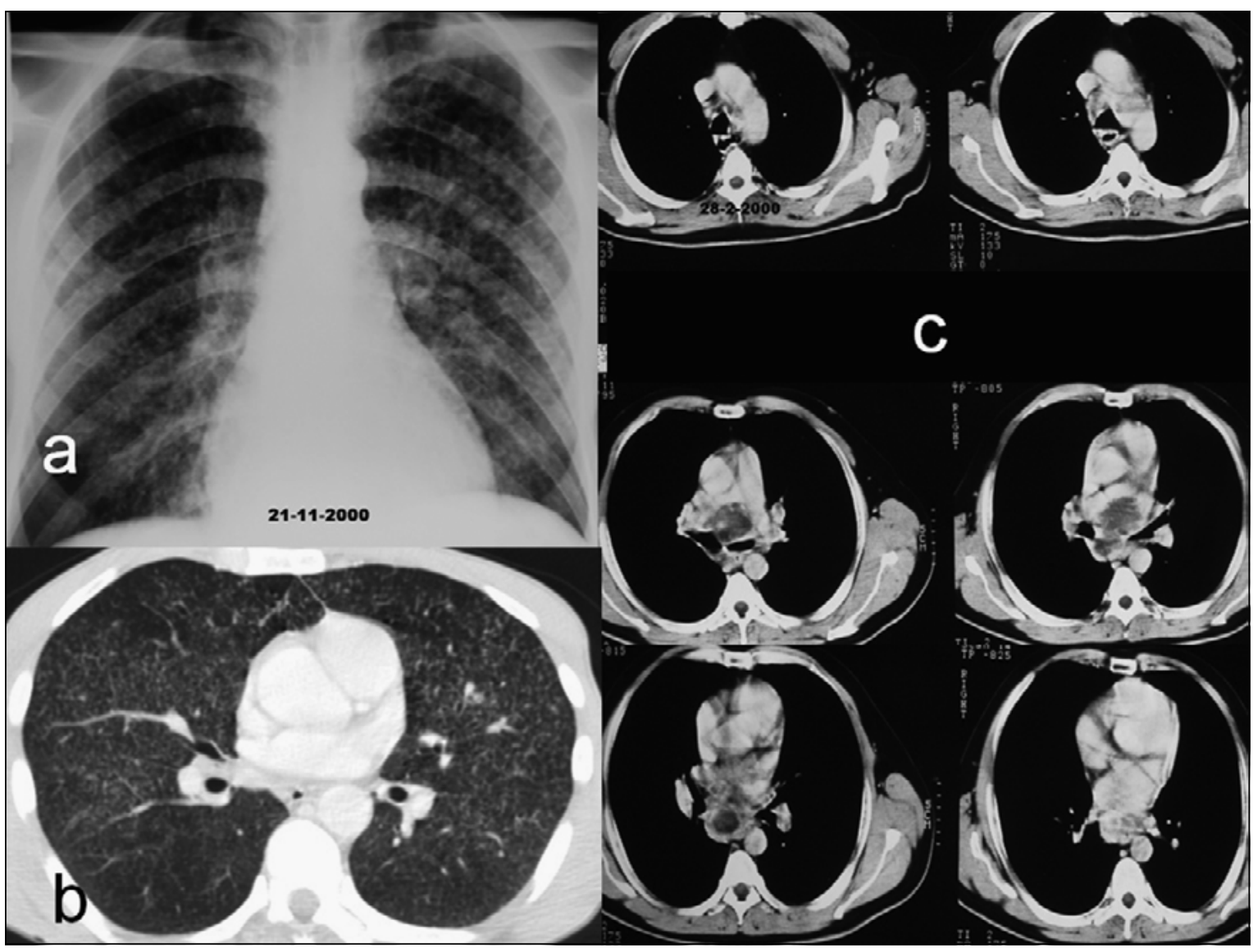

oncológica. La TARV ha reducido su impacto en los grupos infectados por VIH pero no así en los otros grupos de inmunocomprometidos ${ }^{15}$. En Chile se ha reportado un incremento de su participación; así, se ha reportado que del total de micobacterias confirmadas en el Laboratorio Nacional y de Referencia del Instituto de Salud Pública, $15,8 \%$ en $2002,25,6 \%$ en 2003 y 35,0\% en 2004 eran notuberculosas, destacando M. kansasii, M. gordonae, $M$. fortuitum, M. avium, M. intracellulare y M. abscessus ${ }^{40}$.

Se han descrito cinco patrones clínico-radiológicos para la neumonía por estos oportunistas: clásico, síndrome de Lady Windermere, nodular, asociado a acalasia y el patrón de los inmunocomprometidos, que considerando los pacientes con SIDA y $\mathrm{CD}_{4}<50$ a 70 céls $/ \mathrm{mm}^{3}$ y déficit de inmunidad celular, dan cuenta de $50 \%$ de las infecciones por estas bacterias. En este último grupo la neumonía se caracteriza por ser una infección primaria que en $24 \%$ da compromiso extra-toráxico, y donde son más frecuentes las adenopatías y nódulos centrilobulillares, casi miliar en ocasiones, con opacidades y cavitaciones dispersas ${ }^{39}$.

Nocardiaceae y L. pneumophila. La familia Nocardiaceae incluye bacterias ácido-resistentes, grampositivas débiles. Son saprófitas de hábitat naturales, transportadas por vientos, siendo los mecanismos de transmisión más frecuente la inhalación e inoculación. Se comportan como bacterias oportunistas produciendo infección pulmonar invasora o diseminada en el paciente inmunocomprometido. Esta familia incluye a $N$. asteroides, principal responsable de las infecciones, aunque también hay que mencionar a rum $^{41}$. También incluye al género Rhodococcus, donde destaca como patógeno oportunista $R$. equi (antes llamado Corynebacterium equi).

Las Nocardia se diseminan en forma hematógena pudiendo sobrevivir y replicarse en macrófagos y provocan enfermedad broncopulmonar en pacientes inmunocomprometidos con déficit de inmunidad celular como leucemia, infección por VIH, pacientes en tratamiento con corticosteroides y aquellos que han sido sometidos a trasplantes. Las neumonías por Nocardia spp (Figura 5) se manifiestan como consolidaciones (52\%), nódulos grandes o masas $(24 \%)$, cavitaciones $(62 \%)$, efusión pleural (33\%), con predominio en los lóbulos superiores (71\%) y con patrón intersticial en forma ocasional ${ }^{42,43}$.

Rhodococcus equi se presenta en $66 \%$ en SIDA $N$. brasiliensis, $N$. pseudobrasiliensis y $N$. otitidiscavia- 
con $\mathrm{CD}_{4}$ bajo, en promedio 35 céls $/ \mathrm{mm}^{3}$. Muntaner y cols. $(1997)^{44}$, en 45 pacientes encontraron recuento $\mathrm{CD}_{4}<200$ céls $/ \mathrm{mm}^{3}(60,4 \%)$, predominio en lóbulos superiores $(55 \%)$ cavitación $(77 \%)$ y frecuentemente efusión pleural ${ }^{44,45}$.

Legionella pneumophila es una especie aerobia con forma de bacilos, gramnegativa. Es una bacteria ambiental que prefiere cursos de agua y que puede encontrarse en equipos de refrigeración, aire acondicionado y agua caliente. También se le puede encontrar en el plancton al interior de protozoos como Acanthamoeba ${ }^{46}$. La infección en el hombre depende de la inmunidad celular ya que se multiplica en macrófagos alveolares y monocitos. Es más frecuente en pacientes de edad avanzada, falla renal, pacientes sometidos a trasplantes, pacientes con enfermedad pulmonar obstructiva crónica o neoplasias ${ }^{15,47}$.

La neumonía por Legionella spp se caracteriza por una consolidación neumónica de predominio periférica que puede llegar a ser lobar y muchas veces bilateral ${ }^{48-50}$. Tiene un curso progresivo, rápido en 3 a 4 días, y en el caso de los hospederos inmunocomprometidos hay una altas tasa de cavitación y adenopatías hiliares ${ }^{50}$.

\section{Hongos}

Desde la perspectiva de su patogenia los hongos se pueden clasificar como: patógenos primarios y patógenos oportunistas como P. jiroveci, Aspergillus spp. (ie A. fumigatus), Candida spp. (ie C. albicans), C. neoformans y Zygomicetes (Mucor spp, Absidia spp y Rhyzopus spp $)^{51}$. Afortunadamente no se ha reportado infección endógena en Chile por patógenos primarios. En cambio los hongos oportunistas son relevantes en los pacientes inmunocomprometidos con déficit de inmunidad celular.

Pneumocystis jiroveci. Es considerado hoy un hongo dimórfico, cuyo reservorio natural son los humanos y que se adquiere por inhalación. Puede existir una forma trófica, un esporocisto uninucleado, o un quiste ${ }^{52}$. Es un agente frecuente de neumonías en hospederos inmunocomprometidos, especialmente en pacientes con infección por VIH (Figura 6), donde da cuenta de alrededor de 1/3 de las infecciones oportunistas ${ }^{21}$, especialmente en pacientes cuyo recuento de linfocitos $\mathrm{CD}_{4}$ es menor a 200 céls $/ \mathrm{mm}^{3}$. Se describen cuatro patrones asociados a la infección por $P$. jiroveci: neumonía intersticial, donde el compromiso es bronquíolo-intersticial que puede progresar al espacio aéreo y producir fibrosis; formación de neumatoceles o quistes aéreos; neumotórax y muy raramente adenopatías. Sabbagh (1999) ${ }^{20}$ reportó formas alveolo-intersticiales en $55 \%$, intersticiales puras en $42 \%$, fibrosis y quistes en $5 \%$. Además se reporta un predominio en el lóbulo medio (58\%) e inferior (32\%) por sobre el lóbulo superior $(8 \%)^{20}$. La evolución clásica es un cuadro de compromiso intersticial en el que aparecen quistes aéreos y neumotórax

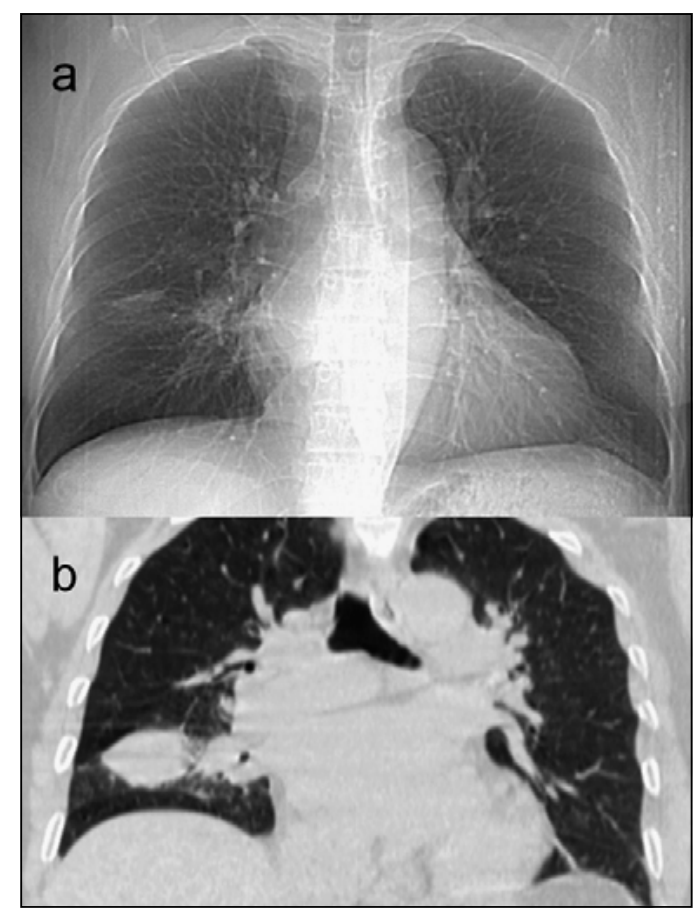

Figura 5. a y b) radiografía digital de tórax y reconstrucción coronal de TAC de tórax: opacidad nodular alargada, mal definida en el lóbulo medio que correspondió a neumonía por Nocardia sp en paciente sometido a trasplante renal.

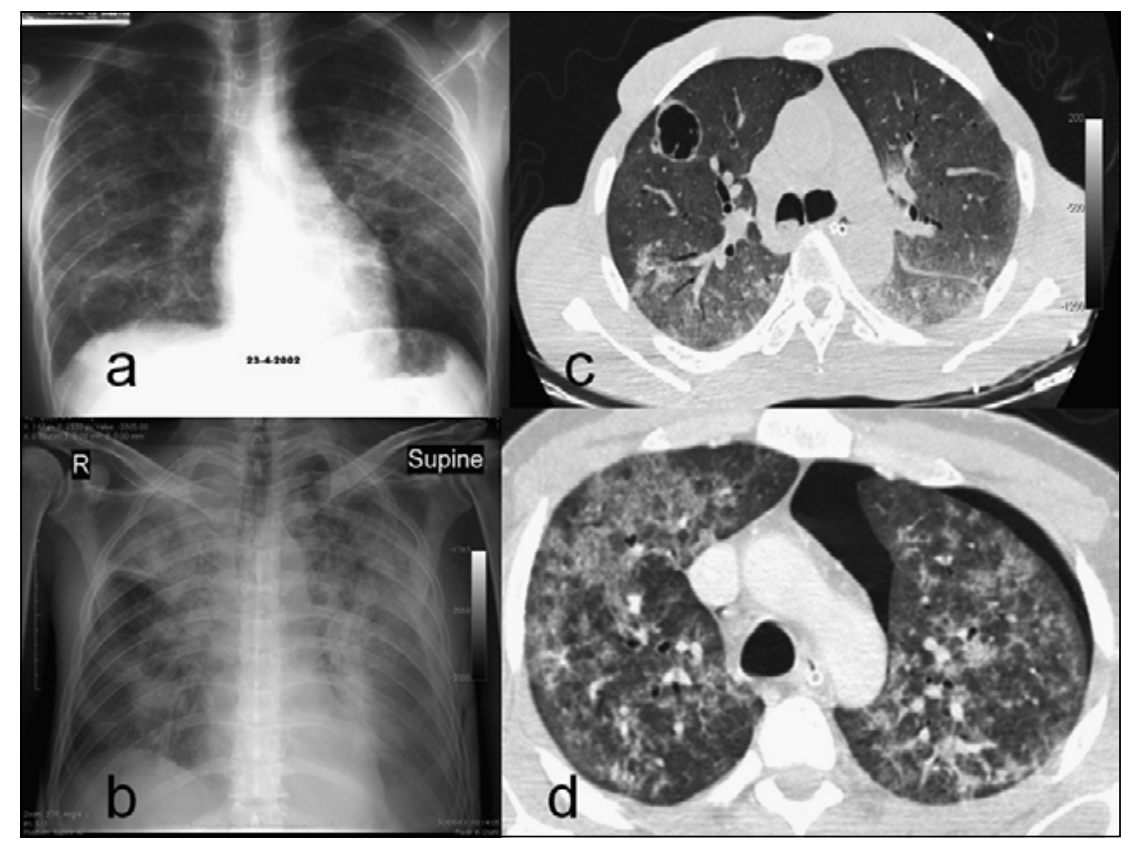

Figura 6. Neumonía por $P$. jiroveci en pacientes con infección por VIH: a) radiografía de tórax PA: múltiples imágenes radiolúcidas con aspecto de quistes en ambos pulmones; b) radiografía de tórax PA: opacidades con aspecto de consolidación en ambos campos pulmonares con predominio central y en el lóbulo superior derecho y efusión pleural izquierda en paciente con SIDA y síndrome de reconstitución inmune; c) TAC de tórax, corte transversal, ventana pulmonar: opacidad difusa en vidrio esmerilado, quiste en lóbulo superior derecho e infiltrados alveolares centrilobulillares en ambos lóbulos superiores; d) TAC de tórax, corte transversal, ventana pulmonar: opacidades en vidrio esmerilado con mosaicismo en el lóbulo superior derecho ("crazy paving") , opacidades difusas en el lóbulo superior izquierdo y neumotórax izquierdo. 


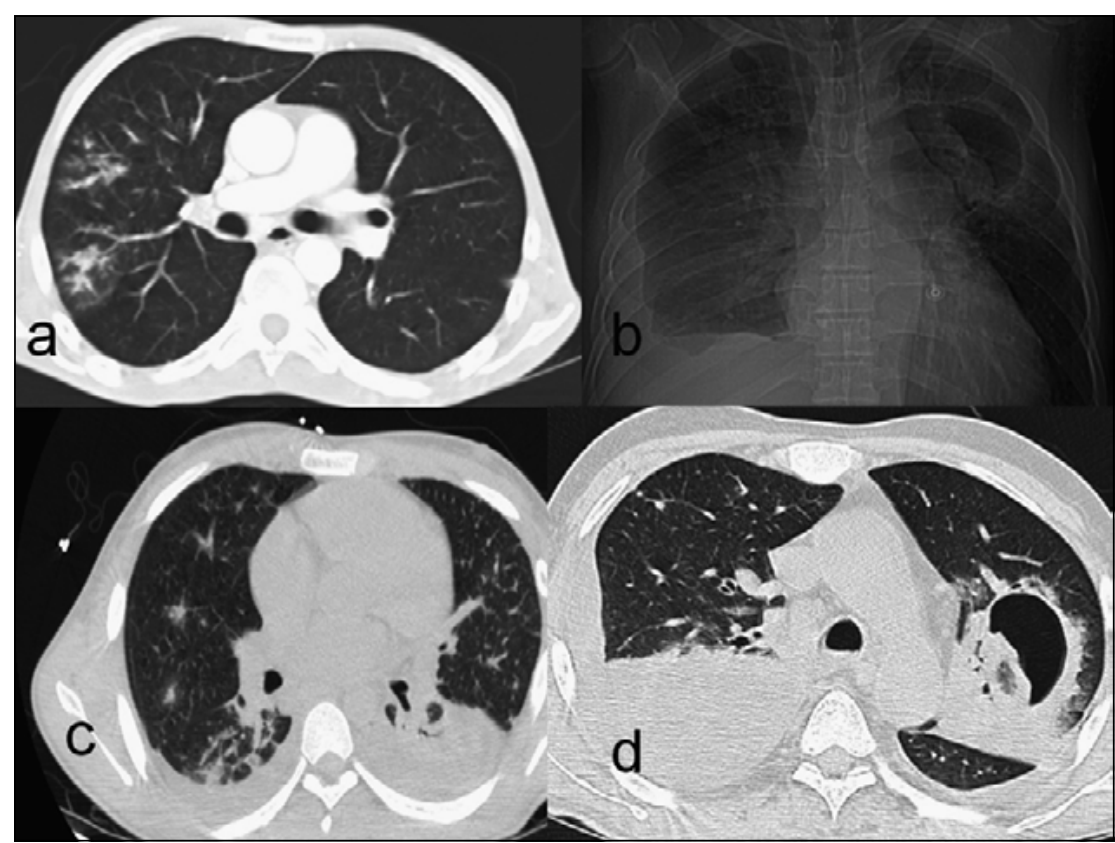

Figura 7. a) TAC de tórax, corte transversal, ventana pulmonar: infiltrados alveolares con "árbol en brote" en paciente oncológico con aspergilosis bronco-invasora; b-d) aspergilosis angio-invasora en pacientes con linfoma: b) scout view: paciente con efusión pleural derecha, opacidades difusas parenquimatosas e imagen cavitaria en el lóbulo superior izquierdo; c) TAC de tórax, corte transversal ventana pulmonar: consolidaciones basales y nódulos con tenue halo en el lóbulo superior derecho; d) el mismo paciente que en b) que presentó un gran nódulo que se cavitó recordando la imagen en "crescente". y que evoluciona con fibrosis asociada ${ }^{52}$. En la TC son características las opacidades en vidrio esmerilado que pueden formar verdaderos mosaicos ("crazy paving"). Así, se ha reportado opacidades apicales en vidrio esmerilado en $70 \%$, patrón en mosaico en $54 \%$, opacidades pobremente demarcadas en $23 \%$ y compromiso homogéneo en vidrio esmerilado en $54 \%$, pudiendo co-existir estas imágenes en un mismo paciente ${ }^{53}$.

Aspergillus fumigatus. En los hospitales se le puede encontrar en el aire, duchas, depósitos de agua y plantas en maceteros. El compromiso pulmonar depende del compromiso inmune del hospedero. Así, el compromiso pulmonar más habitual por Aspergillus en un paciente con hipersensibilidad puede manifestarse como una aspergilosis broncopulmonar alérgica (ABPA), en un sujeto normal como una aspergilosis saprofítica (micetoma), en una unmunodepresión leve como una aspergilosis semiinvasora crónica y en una inmunodepresión intensa como una aspergilosis bronco- o angio-invasora (Figura 7) ${ }^{51,54}$.

La aspergilosis semi-invasora es más frecuente en pacientes con diabetes mellitus, malnutrición, alcoholismo, edad avanzada, uso de corticosteroides, EPOC, es decir, con inmunodepresión leve. Es un cuadro indolente, que puede manifestarse por tos de larga data, fiebre e incluso hemoptisis y cuyos hallazgos anátomo-patológicos incluyen necrosis e inflamación granulomatosa similar a la TBC. Radiológicamente se manifiesta como áreas de consolidación uni o bilaterales, con o sin cavitación o engrosamiento pleural y donde la TAC puede demostrar masas endoluminales o hiliares, neumonitis obstructiva además de áreas de infiltrados difusos con algunos nódulos y cavitación ${ }^{51}$.

La aspergilosis bronco-invasora corresponde a la infección bronquial por Aspergillus comprometiendo y transgrediendo la membrana basal ${ }^{55}$. Se le encuentra en pacientes inmunocomprometidos neutropénicos y pacientes con SIDA $^{54}$. Radiológicamente se manifiesta como una infección de la via aérea fina con opacidades parcheadas, nódulos centrilobulillares e imagen de "árbol en brote". Finalmente, la aspergilosis angioinvasora se encuentra casi exclusivamente en pacientes inmunocomprometidos, como pacientes con neutropenia intensa, sometidos a quimioterapia o a trasplantes, o portadores de enfermedades como leucemia. Los hallazgos característicos en la TAC son nódulos con halo en vidrio esmerilado o imágenes en cuña periféricas. Estas representan zonas de infartos hemorrágicos. Se pueden cavitar apareciendo imágenes radiolúcidas que "marginan" los nódulos por la separación entre tejido necrótico y sano ("signo del crescente"). Aunque la imagen es muy característica, no es patognomónica pudiendo aparecer en infecciones por otros hongos como Candida y Mucor en infecciones virales y en otras condiciones como vasculitis y sarcoma de Kaposi ${ }^{54-56}$.

\section{Otros hongos oportunistas}

La infección pulmonar por C. albicans es infrecuente y ocurre en hospederos intensamente inmunocomprometidos. Los hallazgos radiológicos son inespecíficos. Habitualmente hay consolidación con predominio en los lóbulos inferiores. Ocasionalmente hay compromiso intersticial o micronódulos. La cavitación es rara pero puede haber signo del crecente. Ocurre efusión pleural en $25 \%{ }^{51}$.

La infección por C. neoformans en pacientes inmunocomprometidos puede dar gran compromiso sistémico, típicamente en el sistema nervioso central. Radiológicamente se manifiesta con nódulo único o múltiple (Figura 8), consolidaciones y compromiso intersticial, siendo esta última más común en pacientes con SIDA ${ }^{51}$. La efusión pleural y las adenopatías son hallazgos frecuentes en hospederos inmunocomprometidos.

Los Zygomicetes, que incluyen a Mucor spp, Rhyzopus spp y Absidia spp son raras causas de infección pulmonar. Son más frecuentes en pacientes con leucemia, en inmunocomprometidos profundos y en diabéticos. Al igual que Aspergillus spp, en población de inmunocomprometidos producen compromiso angioinvasor, grandes cavitaciones rápidamente progresivas y cavitación con o sin signo del crescente. A menudo tienen curso fatal ${ }^{51}$. 


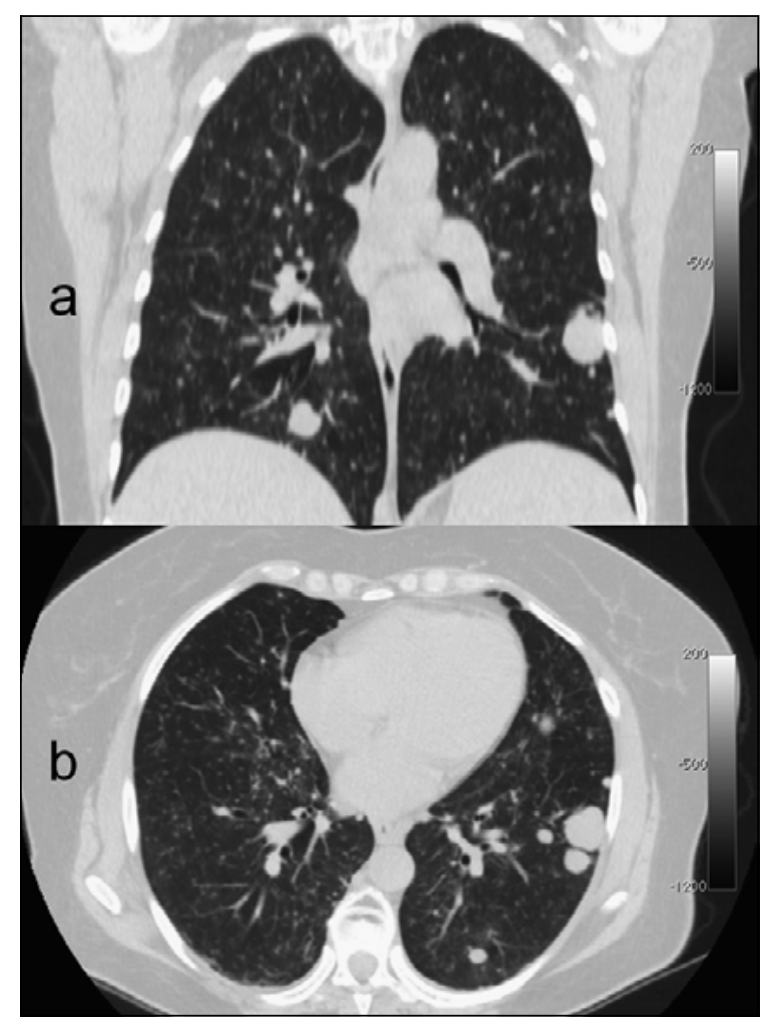

Figura 8. Paciente portador de una leucemia que durante su evolución presentó múltiples nódulos y nodulillos en ambos pulmones que correspondieron a neumonía por C. neoformans: en a) reconstrucción coronal y b) corte transversal.

\section{Virus}

Los agentes etiológicos de neumonías virales según Kim y cols. $(2002)^{57}$, se pueden agrupar en aquellos que comprometen principalmente a pacientes inmunocompetentes: virus influenza y parainfluenza, hantavirus, virus de Epstein-Barr, adenovirus; e inmunocomprometidos: virus herpes simplex, virus varicela-zoster, $\mathrm{CMV}$, virus sarampión y adenovirus. Sarampión y varicela son muy infrecuentes como causas de neumonías en el adulto, gracias los programas de vacunación, en el caso de sarampión, y a la frecuente primoinfección por varicela en la infancia, aunque pueden presentarse en el paciente inmunocomprometido. Ambas infecciones producen una neumonitis donde dominan los nódulos centrilobulillares y la atenuación en vidrio esmerilado. En la varicela el compromiso es dominantemente caracterizado por nódulos pequeños (3-4 mms). El adenovirus también produce nodulillos centrilobulillares, pero tiene un mayor compromiso parenquimatoso con atelectasias y bronquiolitis, caracterizándose por áreas de retención de aire y defectos de perfusión. Muchas veces hay bronquiectasias asociadas que pueden quedar como secuelas; es frecuente la efusión pleural $(63 \%)^{58,59}$. Citomegalovirus es frecuente en pacientes inmunocomprometidos que han sido sometidos a trasplantes y en SIDA, habiéndose invocado mecanismos patogénicos diferentes en estos dos grupos. En los sometidos a trasplantes se trataría de un mecanismo inmune asociado a los linfocitos $\mathrm{T}$ en respuesta a antígenos inducidos expresados en el pulmón, mientras que en el SIDA existiría una acción citopatogénica directa producida por la replicación viral. Esto explicaría la baja carga de virus necesaria para producir neumonía en los primeros y la alta carga en los segundos. Radiológicamente, la neumonía por $\mathrm{CMV}$ en pacientes sometidos a trasplantes se expresa como infiltrados con finos nódulos $(60-90 \%)$ y consolidación $(40-70 \%)^{60,61}$. En pacientes inmunodeprimidos en general, se ha encontrado en $100 \%$ "vidrio esmerilado", en $90 \%$ líneas, en $54,5 \%$ nódulos centrilobulillares y en $45,4 \%$ dilataciones bronquiales $^{62}$. En pacientes con SIDA se ha encontrado vidrio esmerilado en $19 \%$ y micronódulos en $48 \%{ }^{62}$. De estos estudios se desprende que lo más característico en CMV es la presencia de micronódulos y compromiso del intersticio alveolar.

\section{Un ejemplo y Conclusiones}

Para observar cómo opera el proceso de inferencia Bayesiana consideremos el siguiente ejemplo. Supongamos que un paciente con infección por VIH tiene un cuadro neumónico y se obtienen las imágenes mostradas en la Figura 7 (b-d). Como se trata de un paciente con SIDA, antes de observar la imagen (B) consideramos las frecuencias de los diferentes agentes $\left(\mathrm{A}_{\mathrm{j}}\right)$ (Tabla 1) y atribuimos las probabilidades a priori $\left(P\left(A_{j}\right)\right.$; Tabla 3$)$.

Tabla 3. Ejemplo de aplicación del teorema de Bayes en el diagnóstico de una neumonía de un paciente inmunocomprometido, en presencia de la imagen mostrada en la Figura 7 (b-d)

\begin{tabular}{|c|c|c|c|c|c|}
\hline $\begin{array}{l}\text { Agente } \\
\left(A_{j}\right)\end{array}$ & Frecuencia & $\begin{array}{c}\text { Probabilidad } \\
\text { a priori } \\
\left(\mathrm{P}\left(\mathrm{A}_{\mathrm{j}}\right)\right)\end{array}$ & $\begin{array}{l}\text { Función de } \\
\text { verosimilitud } \\
\left(P\left(B / A_{j}\right)\right)\end{array}$ & $\begin{array}{c}\text { Productos } \\
\left(P\left(B / A_{j}\right)\right. \\
\left.P\left(A_{j}\right)\right)\end{array}$ & $\begin{array}{l}\text { Probabilidad } \\
\text { a posteriori } \\
(\mathrm{P}(\mathrm{A} / \mathrm{B}))\end{array}$ \\
\hline P. jiroveci & 0,3771 & 0,4767 & 0 & 0 & 0 \\
\hline Bacterias comunes & 0,233 & 0,2945 & 0,005 & 0,0015 & 0,1762 \\
\hline M. tuberculosis & 0,122 & 0,1542 & 0,02 & 0,0031 & 0,3691 \\
\hline M. no TBC & 0,021 & 0,0265 & 0,015 & 0,0004 & 0,0476 \\
\hline Bacterias no comunes & 0,017 & 0,0215 & 0,017 & 0,0004 & 0,0437 \\
\hline Virus & 0,013 & 0,0164 & 0 & 0 & 0 \\
\hline Aspergillus spp & 0,004 & 0,0050 & 0,6 & 0,00304 & 0,3631 \\
\hline CMV & 0,004 & 0,0050 & 0 & 0 & 0 \\
\hline Total $(\Sigma)$ & 0,7911 & 1 & 0,657 & 0,0084 & 1,0000 \\
\hline
\end{tabular}

$P(A)=$ frecuencia/ $/$ frecuencias. La función de verosimilitud en este caso es una estimación aproximada a manera de ejemplo. Ver texto. 
Tabla 4. Relación entre los patrones radiológicos y el agente causal

$\begin{array}{ll}\text { Patrón radiológico } & \text { Agentes } \\ \text { Consolidación lobar } & \begin{array}{l}\text { S. pneumoniae, K. pneumoniae, Enterobacter sp. (ocasional), } \\ \text { L. pneumophila }\end{array} \\ \begin{array}{l}\text { Bronconeumonía } \\ \text { (segmentaria, parcheada) }\end{array} & \begin{array}{l}\text { S. aureus, anaerobios estrictos, S. pneumoniae, Enterococcus } \\ \text { sp., A. baumannii, P. aeruginosa, Enterobacter sp. }\end{array} \\ \text { Intersticio-alveolar (neumonía atípica) } & \text { M. pneumoniae C. pneumoniae, virus } \\ \text { Patrón aspirativo } & \text { Anaerobios estrictos } \\ \text { Micrododular } & \text { M. tuberculosis (miliar), varicela, citomegalovirus } \\ \text { Cavitación frecuente } & \text { M. tuberculosis, S. aureus, bacilos Gram(-), N. asteroides } R . \\ \text { Macronodular o consolidaciones } & \text { equi, A. fumigatus, Zygomicetes } \\ \text { pseudonodulares } & \text { S. aureus, hongos, N. asteroides, R. equi, Zygomicetes } \\ \text { Adenopatías dominantes } & \text { M. tuberculosis, M. avium-c } \\ \text { Efusión pleural frecuente (> 33\%) } & \text { K. pneumoniae, P. aeruginosa, S. aureus, N. asteroides, R. } \\ & \text { equi; anaerobios estrictos }\end{array}$

Como suponemos que es una partición del espacio muestral, éstas suman 1. Después, de acuerdo al conocimiento del radiólogo, analizamos cada posibilidad y atribuimos las probabilidades condicionales $P\left(B / A_{j}\right)$ que en este caso, a manera sólo de ejemplo, fueron estimadas en forma aproximada por los autores, aunque lo ideal sería contar con estos valores. Por ejemplo un buen estimador de $\mathrm{P}$ (nódulo cavitado/bacteria común) sería la proporción de neumonías por bacterias comunes que se cavitan. Las $P(B /$ $A$ ) en su conjunto constituyen la función de verosimilitud. Finalmente, podemos obtener las probabilidades para cada agente mediante la fórmula [1]. Como podemos ver (Tabla 3 ), basados en las frecuencias a priori de la literatura y en la función de verosimilitud construida, los diagnósticos más probables para este caso serían: TBC y aspergilosis.

Como vemos, la metodología de la inferencia Bayesiana permite ordenar la aproximación diagnóstica del radiólogo identificando dos componentes: la probabilidad a priori que está determinada por la epidemiología y los antecedentes clínicos y la función de verosimilitud que se refiere a las características de la imagen.

\section{Tabla 5. Hallazgos radiológicos frecuentes según agente causal}

\begin{tabular}{|c|c|}
\hline Agente & Hallazgos frecuentes o propios \\
\hline \multicolumn{2}{|l|}{ Bacterias } \\
\hline Enterococcus spp. & Patrón neumónico o bronconeumónico inespecífico \\
\hline S. aureus & $\begin{array}{l}\text { Patrón bronconeumónico en inmunocompetentes. Consolidaciones, nódulos centrilobulillares y ramificaciones en "árbol en brote" en la TAC. } \\
\text { Abscesos y neumatocele. Efusión pleural. En IC, patrón clásico o diseminación hematógena (émbolos sépticos). Nódulos de predominio sub- } \\
\text { pleural. Signo del "vaso aferente" }\end{array}$ \\
\hline K. pneumoniae & $\begin{array}{l}\text { Consolidación lobar. Expansión del lóbulo comprometido curvando las cisuras (30\%). Cavitación. Abscesos. Efusión pleural en } 60 \text { a } 70 \% \text { de } \\
\text { los casos (Moon et al., 1995) }\end{array}$ \\
\hline A. baumannii & Patrón bronconeumónico inespecífico \\
\hline$P$. aeruginosa & Bronconeumonía extensa pan lobular,opacidades nodulares, compromiso reticular, cavitación, efusión pleural \\
\hline Enterobacter sp. & Patrón bronconeumónico inespecífico \\
\hline Anaerobios estrictos & $\begin{array}{l}\text { Patrón de neumonía aspirativa. Segmentos posteriores de los lóbulos superiores y apicales de los lóbulos inferiores. Cavitación. Neumonía } \\
\text { necrosante. Efusión pleural. Empiema }\end{array}$ \\
\hline M. tuberculosis & $\begin{array}{l}\text { En inmunocompetentes: Cavitación. Calcificación. Fibrosis. Adenopatías. En IC: Adenopatías. Micronódulos (miliar). Consolidación. Efusión } \\
\text { pleural }\end{array}$ \\
\hline Micobacterias no-tuberculosas & $\begin{array}{l}\text { En inmunocompetentes: patrones similares a TBC } \\
\text { En IC: Adenopatías. Opacidades. Cavitaciones. Infiltrados centrilobulillares ("árbol en brote ") en la TAC }\end{array}$ \\
\hline N. asteroides & Consolidaciones. Nódulos grandes o masas. Cavitaciones. Efusión pleural \\
\hline R. equi & Consolidacion. Cavitación. Efusión pleural \\
\hline L. pneumophila & Consolidación. Curso rápido. Cavitación. Adenopatías \\
\hline \multicolumn{2}{|l|}{ Hongos } \\
\hline $\begin{array}{l}\text { P. jiroveci } \\
\text { A. fumigatus }\end{array}$ & $\begin{array}{l}\text { Neumonia intersticial. Neumatoceles. Neumotórax. En la TAC opacidades en vidrio esmerilado, mosaicos ("crazy paving"). Predominio apical. } \\
\text { En inmunocompetentes: ABPA y micetoma. En IC: i) aspergilosis semi-invasora crónica: Consolidación, neumonitis obstructiva, infiltrados } \\
\text { difusos, nódulos y cavitación. ii) aspergilosis broncoinvasora: opacidades parcheadas, nódulos centrilobulillares e imagen de "árbol en brote" } \\
\text { en la TAC. iii) aspergilosis angio-invasora: Nódulos con halo. Imágenes en cuña periféricas. Signo del crescente }\end{array}$ \\
\hline C. albicans & Consolidación. Compromiso intersticial o micronódulos. Efusión pleural \\
\hline C. neoformans & Nódulos, consolidaciones, compromiso intersticial. Efusión pleural, adenopatías \\
\hline $\begin{array}{l}\text { Zygomicetes } \\
\text { Virus }\end{array}$ & Consolidaciones, cavitaciones rápidamente progresivas. A menudo de curso fatal \\
\hline Varicela-zoster & Neumonitis donde dominan los nódulos centrilobulillares y la atenuación en vidrio esmerilado. Nódulos pequeños (3-4 mms). \\
\hline Adenovirus & Nodulillos centrilobulillares, atelectasias, bronquiolitis, retención de aire, defectos de perfusión. Bronquiectasias secuelares. Efusión pleural \\
\hline Citomegalovirus & Infiltrados, finos nódulos centrilobulillares, consolidación, vidrio esmerilado, líneas \\
\hline
\end{tabular}


En las imágenes de las neumonías del paciente inmunocomprometido encontramos dos situaciones: neumonías que ocurren por agentes etiológicos habituales, pero que cambian sus manifestaciones en las imágenes a causa del inmunocompromiso del paciente, como ocurre por ejemplo en las bacterias del grupo ESKAPE, las bacterias anaerobias, las micobacterias y Aspergillus spp.; y neumonías por microorganismos que sólo (o casi sólo) se presentan en inmunocomprometidos, por ejemplo $N$. asteroides, $R$. equi, Candida spp., C. neoformans, Zygomicetes y CMV. Así, en la primera situación las imágenes serán similares a las de pacientes inmunocompetentes, pero serán más frecuentes las complicaciones como efusión, empiemas y abscesos ${ }^{34}$, o en el caso de las micobacterias predominarán cuadros miliares y adenopatías ${ }^{37-39} \mathrm{o}$ en el caso de Aspergillus spp., las formas bronco o angio-invasoras ${ }^{51}$. En la segunda situación, los patrones descritos, más o menos característicos, provienen de pacientes inmunocomprometidos $^{51,53,62}$.

$\mathrm{Al}$ igual que lo que ocurre en las $\mathrm{NAC}^{63}$, en la aproximación diagnóstica de imágenes en la neumonía del paciente inmunocomprometido pesan los antecedentes clínicos y epidemiológicos que permiten tener una idea $a$ priori de los posibles agentes etiológicos de la neumonía y los hallazgos de imagen que aunque en general no son patognomónicos y existe mucha superposición, es decir, presentan algunas características que orientan en una $\mathrm{u}$ otra dirección (Tablas 4 y 5). La adecuada valoración de la probabilidad a priori y la función de verosimilitud son las que permiten en definitiva una buena orientación diagnóstica.

\section{Resumen}

Introducción: La población de pacientes inmunocomprometidos se ha incrementado en las últimas décadas. Gran parte de estos pacientes presenta en algún momento complicaciones infecciosas, entre ellas la neumonía, lo que constituye un desafío diagnóstico que debe ser rápido y acertado. Objetivo: Revisar las bases del diagnóstico de las neumonías del paciente inmunocomprometido. Ordenados por la metodología de la inferencia Bayesiana, muy relevante en la atribución diagnóstica, destacamos y revisamos los pilares fundamentales en el diagnóstico de las neumonías del inmunocomprometido: la epidemiología, los antecedentes clínicos incluyendo el tipo de inmunodepresión, que pesan en la probabilidad de atribución a priori de un agente etiológico, y finalmente, los hallazgos en la imagen (o función de verosimilitud). Conclusión: Los hallazgos de imagen que, aunque en general no son patognomónicos y existe mucha superposición, presentan algunas características que orientan en una u otra dirección. La adecuada valoración de la probabilidad a priori y la función de verosimilitud son las que permiten en definitiva una buena proposición diagnóstica.

\section{Referencias bibliográficas}

1.- Murray J F, Mills J. Pulmonary infectious complications of human immunodeficiency virus infection: part 1. Am Rev Respir Dis 1990; 141: 1356-72.

2.- Ho Y W, Effmann E L, Godwin J D. Pulmonary infections in immunocompromised hosts: the importance of correlating the conventional radiologic appearance with the clinical setting. Radiology 2000; 217: 647-56

3.- Lyman G H, Rolston K V I. How we treat febrile neutropenia in patients receiving cancer chemotherapy. J Oncol 2010; 6 (3): 3149-52.

4.- Nash G. Pathologic features of the lung in the immunocompromised host. Hum Pathol 1982; 13: 841-58.

5.- Ashby D. Bayesian statistics in medicine: a 25 year review. Stat Med 2006; 25 (21): 3589-631.

6.- Canals M. Bases cuantitativas del análisis de imágenes médicas: información e inferencia Bayesiana. Rev Med Chile 2003; 131: 553-61.

7.- Medina E, Kaempffer A M. Mortalidad del adulto en Chile. Rev Med Chile 2000; 128: 1144-9.

8.- Undurraga A, Fernández P. Neumonía adquirida en la comunidad. En Enfermedades
Respiratorias (Rodríguez JC \& Undurraga A eds); 2010: 677-703.

9.- Fernández M, Zagolín M, Ruiz M, Martínez M A, Díaz J C. Neumonía adquirida en la comunidad que se hospitaliza: estudio etiológico. Rev Med Chile 2003; 131: 498-504.

10.- Díaz A, Torres C, Flores L J, García P, Saldías F. et al. Neumonía neumocócica adquirida en la comunidad en adultos hospitalizados. Rev Med Chile 2003; 131: 505-14.

11.- Díaz A, Fuentes G, Couble B, Uribe R, Mercado G, Soza A, et al. Etiología de la neumonía adquirida en la comunidad en adultos hospitalizados en Santiago, Chile: implicancias para las guías clínicas. Rev Chil Enf Respir 2005; 21: 23-32.

12.- Díaz A, Barria P, Niederman M, Restrepo M I, Dreyse J, Fuentes G, et al. Etiology of community-acquired pneumonia in hospitalized patients in Chile. The increasing prevalence of respiratory viruses among classic pathogens. Chest 2007; 131: 779-87.

13.- Ramírez J A. Neumonia nosocomial. En Enfermedades Respiratorias (Rodríguez JC \& Undurraga A eds); 2010: 703-17.

14.- Álvarez A M, Bavestrello L, Labarca J, Calvo M. Tratamiento de la neumonía asociada a ventilación mecánica. Rev Chil Infectol 2001 ; 18 (2): 41-57.

15.- Muller N L, Franquet T, Lee K S. Imaging of pulmonary infections. 2007; 1st Edition. Lippincott Williams \& Wilkins.

16.- Venkatesan P, Gladman J, Macfarlane J T, Barer D, Berman P, Kinnear W, et al. A hospital study of community acquired pneumonia in the elderly. Thorax 1990; 45: 254-8.

17.- Rello J, Rodríguez R, Jubert P, Alvarez B. Severe community acquired pneumonia in the elderly: epidemiology and prognosis. Clin Infect Dis 1996; 23: 723-8.

18.- Riquelme R, Riquelme M, Rioseco M L, Gómez V, Cárdenas G, Torres C. Neumonía adquirida en la comunidad en el anciano hospitalizado. Aspectos clínicos y nutricionales Rev Med Chile 2008; 136: 587-93.

19.- Rubin R H, Ferraro M J. Understanding and diagnosing infectious complications in the immunocompromised host. Hematol Oncol Clin North Am 1993; 7: 795-812.

20.- Sabbagh E. Neumonias en el inmunodeprimido. Rev Chil Radiol 1999; 5 (2): 43-7.

21.- Chernilo S, Trujillo S, Kahn M, Paredes M, Echevarría G, Sepúlveda C. Enfermedades 
pulmonares en pacientes infectados con VIH hospitalizados en el Instituto Nacional del Tórax. Rev Med Chile 2005; 133: 517-24.

22.- Pérez C, García P, Calvo M, Labarca J, Bustos M, Beroíza T, et al. Etiología de la neumonía en pacientes chilenos infectados por el virus de la inmunodeficiencia humana. Rev Chilena Infectol 2011; 28 (4): 343-8.

23.- Brockmann P, Viviani T, Peña A. Compromiso pulmonar en la infección por virus de inmunodeficiencia humana en niños. Rev Chilena Infectol 2007; 24 (4): 301-5.

24.- Finkelstein D M, Williams P L, Molenberghs G, Feinberg J, Powderly W G, Kahn J, et al. Patterns of opportunistic infections in patients with HIV infection. J Acquir Immune Defic Syndr Hum Retrovirol 1996; 12: 38-45.

25.- McLoud T C, Naidich D P. Thoracic disease in the immunocompromised patient. Radiol Clin North Am 1992; 30: 525-54.

26.- Sander H. Enterococos resistentes a vancomicina: ¿Infección emergente inminente? Rev Chilena Infectol 2002; 19 (1): 50-5.

27.- Tanaka N, Matsumoto T, Kuramitsu T, Nakaki H, Ito K, Uchisako H, et al. High resolution $\mathrm{CT}$ findings in community-acquired pneumonia. J Comput Assist Tomog. 1996; 20: 600-8.

28.- Reittner P, Ward S, Heyneman L, Johkoh T, Müller N L. Pneumonia: high-resolution CT findings in 114 patients. Eur Radiol 2003; 13: 515-21.

29.- Moon W K, Im J G, Yeon K M, Han M C. Complications of Klebsiella pneumonia: CT evaluation. J Comput Assist Tomogr. 1995; 19 : 176-81.

30.- Winer-Muram H T, Jennings S G, Wunderink R G, Jones C B, Leeper K V Jr. Ventilatorassociated Pseudomonas aeruginosa pneumonia: Radiographic findings. Radiology. 1995; 195: 247-52.

31.- Macfarlane J, Rose D. Radiographic features of staphylococcal pneumonia in adults and children. Thorax. 1996; 51: 539-40.

32.- Kaye M G, Fox M J, Bartlett J G, Braman S S, Glassroth J. The clinical spectrum of Staphylococcus aureus pulmonary infection. Chest. 1990; 97: 788-92.

33.- Bartlett JG. Anaerobic bacterial infections of the lung and pleural space. Clin Infect Dis 1993; 16(4): S248-S255.

34.- Conces D J Jr. Bacterial pneumonia in immunocompromised patients. J Thorac Imaging 1998; 13 (4): 261-70.

35.- Farga V, Caminero J A. Tuberculosis, 3ra edición. Editorial Mediterráneo, Santiago y Buenos Aires. 2011.

36.- Harisinghani M G, McLoud T C, Shepard, J A O, Ko J P, Shroff M M, Mueller P R.
Tuberculosis from head to toe. RadioGraphics 2000; 20: 449-70.

37.- Leung A N. Pulmonary tuberculosis: the essentials. Radiology. 1999; 210: 307-22.

38.- Laissy J P, Cadi M, Boudiaf Z E, Casalino E, Crestani B, Bouvet E, et al. Pulmonary tuberculosis: computed tomography and highresolution computed tomography patterns in patients who are either HIV-negative or HIVseropositive. J Thorac Imaging 1998; 13: 58-64.

39.- Erasmus J J, McAdams H P, Farrell M A, Patz E F. Pulmonary nontuberculous mycobacterial infections: radiologic manifestations. Radiographics 1999; 19: 1487-503.

40.- Araya P, Velasco M, Fernández J. Identificación rápida de micobacterias no tuberculosas mediante análisis de patrones de restricción. Rev Med Chile 2006; 134: 868-73.

41.- González P, Cona E. Nocardia asteroides. Rev Chilena Infectol 2006; 23 (3): 359.

42.- Feigin D S. Nocardiosis of the lung: Chest radiographic findings in 21 cases. Radiology 1986; 159: 9-14

43.- Kramer M R, Uttamchandani R B. The radiographic appearance of pulmonary nocardiosis associated with AIDS. Chest 1990; 98; 382-5.

44.- Muntaner L, Leyes M, Payeras A, Herrera M, Gutiérrez A. Radiologic features of Rhodococcus equi pneumonia in AIDS. Eur J Radiol 1997; 24: 66-70.

45.- Rabagliati R, Morales A, Baudrand R, Jorquera J, Oddó D, García P, et al. Neumonía cavitada por Rhodococcus equi en paciente inmunocomprometido no infectado por virus de inmunodeficiencia humana. Caso clínico y revisión. Rev Chilena Infectol 2005; 22 (2): 155-60.

46.- Ulloa M T. Legionella pneumophila. Rev Chilena Infectol 2008; 25 (3): 208.

47.- Tan M J, Tan J S, Hamor R H, File T M, Breiman R F. The radiologic manifestations of Legionnaire's disease. Chest 2000; 117; 398-403.

48.- Kroboth F J, Yu V L, Reddy S C, Yu AC. Clinico radiographic correlation with the extent of Legionnaire disease. Am J Roentgenol 1983; 141: 263-8.

49.- Pedro-Botet M L, Sabria-Leal M, Haro M, Rubio C, Giménez G, Sopena N, et al. Nosocomial and community-acquired Legionella pneumonia: Clinical comparative analysis. Eur Respir J. 1995; 8: 1929-33.

50.- Coletta F S, Fein A M. Radiological manifestations of Legionella/Legionella-like organisms. Semin Respir Infect 1998; 13: 109-15.

51.- McAdams H P, Rosado M, Templeton P A,
Lesar M, Morán C A. Thoracic mycoses from opportunistic fungi: radiologic-pathologic correlation. Radiographics 1995; 15: 271-86.

52.- Chernilo S. Compromiso pulmonar en pacientes VIH(+). En Enfermedades Respiratorias (Rodríguez JC \& Undurraga A eds); 2010: 867-901.

53.- Vogel M N, Brodoefel H, Hierl T, Beck R, Bethge W A, Claussen C D, et al. Differences and similarities of cytomegalovirus and pneumocystis pneumonia in HIV-negative immunocompromised patients-thin section CT morphology in the early phase of the disease. Br J Radiol 2007; 80: 516-23.

54.- Franquet T, Muller N L, Giménez A, Guembe P, de la Torre J, Bagué S. Spectrum of pulmonary aspergillosis: histologic, clinical, and radiologic findings. RadioGraphics 2001; 21: 825-37.

55.- Logan P M, Muller N L. CT manifestations of pulmonary aspergillosis. Crit Rev Diagn Imaging 1996; 37: 1-37.

56.- Marchiori E, Souza A S, Oliveira I, Jaramillo A. Invasión vascular por aspergilosis como complicación pulmonar de las enfermedades hematológicas malignas: evaluación por tomografía computada. Rev Chil Radiol 2003; 9 (1): 5-9.

57.- Kim E A, Lee K S, Primack S L, Yoon H K, Byun H S, Kim T S, et al. Viral pneumonias in adults: radiologic and pathologic findings. RadioGraphics 2002; 22: S137-49.

58.- Han B K, Son J A, Yoon H K, Lee S I. Epidemic adenoviral lower respiratory tract infection in pediatric patients: radiographic and clinical characteristics. Am J Roentgenol 1998; 170: $1077-80$

59.- Kim J S, Ryu C W, Lee S I, Sung D W, Park C K. High-resolution CT findings of varicella-zoster pneumonia. Am J Roentgenol 1999; 72: 113-6.

60.- Kang E Y, Patz E F, Muller N L. Cytomegalovirus pneumonia in transplant patients: CT findings. J Comput Assist Tomogr 1996; 20: 295-9.

61.- Moon J H, Kim E A, Lee K S, Kim T S, Jung K J, Song J H. Cytomegalovirus pneumonia: high-resolution CT findings in ten non-AIDS immunocompromised patients. Korean J Radiol 2000; 1: 73-78.

62.- Kim H S, Lee J S. Cytomegalovirus pneumonia in immunocompromised patients: HRCT findings. J Korean Radiol Soc 1999; 41: 1133-8.

63.- Gil R, Fernández P, Sabbagh E. Diagnóstico clínico-radiológico de la neumonía del adulto adquirida en la comunidad. Rev Chil Infectol 2005; 22 (S): S26-S31. 